\title{
Trends and variability in demographic indicators of a recovering population of green sea turtles Chelonia mydas
}

\author{
Susan E. Piacenza ${ }^{1,4, *}$, George H. Balazs ${ }^{2}$, Stacy K. Hargrove ${ }^{3}$, Paul M. Richards ${ }^{3}$, \\ Selina S. Heppell ${ }^{1}$ \\ ${ }^{1}$ Department of Fisheries and Wildlife, Oregon State University, Corvallis, OR 97330, USA \\ ${ }^{2}$ NOAA Pacific Islands Fisheries Science Center, Honolulu, HI 96818, USA \\ ${ }^{3}$ NOAA Southeast Fisheries Science Center, Miami, FL 33149, USA \\ ${ }^{4}$ Present address: Department of Biology, Occidental College, Los Angeles, CA 90041, USA
}

\begin{abstract}
Multiple populations of green sea turtles Chelonia mydas show signs of population recovery. In Hawaii (USA), green turtles have increased $5.4 \% \mathrm{yr}^{-1}$ since 1973, but fluctuations in census counts of nesting females make recovery diagnosis difficult. Evaluating demographic rates for temporal change and in relation to population density, and indicators of recruitment to sea turtle nesting populations, will ultimately improve population assessments. Using linear mixed and multistate open robust design models, we estimated the demographic indicators (DIs) of size at maturity, nester carapace length, breeding probability, and adult female survival using 3677 tagged nesting green turtles from 1973 to 2010 in Hawaii. To evaluate changes with density, we correlated the DIs with nesting female counts. We estimated size at maturity, assuming that newly tagged nesters are new recruits and that first-time nesters have statistically significant smaller carapace length than recaptures, but the difference in size was only $\sim 0.5 \mathrm{~cm}$. Mean nester carapace length (range: $89.21-91.69 \mathrm{~cm}$ ) and breeding probability (range: $0.0766-0.444 \mathrm{yr}^{-1}$ ) showed directional changes over time, suggesting shifts in age structure that could be due to recruitment. The top-ranked model predicted constant female survival over time $\left(S=0.929 \mathrm{yr}^{-1}, 95 \% \mathrm{CI}\right.$ : 0.924-0.933, model likelihood $=1.00$ ). Counter to our hypothesis based on density-dependence, breeding probability increases with increasing nester abundance. This work contributes to a growing set of studies evaluating sea turtle demography for temporal variability and is the first for Hawaiian green turtles. Our study demonstrates that some easily monitored demographic variables may serve as indicators of population change.
\end{abstract}

KEY WORDS: Breeding probability - Density dependence $\cdot$ Detection probability - Hawaii · Population recovery $\cdot$ Survival $\cdot$ Size at maturity

\section{INTRODUCTION}

Some populations of green sea turtles Chelonia mydas have experienced remarkable recovery from over-exploitation in the last decades, but with a great deal of interannual fluctuation in the numbers of nesters and nests, the primary demographics monitored by biologists (Chaloupka et al. 2008, NOAA \&

${ }^{*}$ Corresponding author: susiepiacenza@gmail.com
USFWS 2015). Populations undergoing recovery often display wide fluctuations in abundance and population growth rates. These fluctuations could be the result of demographic stochasticity, particularly early on in the recovery process, inter- and intra-specific interactions, or environmental variation (Sæether et al. 2004, Shelton \& Mangel 2011). Regardless of the cause, interannual variability in abundance makes it

(C) The authors 2016. Open Access under Creative Commons by Attribution Licence. Use, distribution and reproduction are unrestricted. Authors and original publication must be credited. 
difficult to determine population trends to quantify the rate of recovery and to make predictions.

Variation in life-history traits occurs across species, populations, and individuals (Gotthard \& Nylin 1995, Cam et al. 2002, Bjørkvoll et al. 2012). In the case of overexploited or endangered species, population perturbations may have important and persistent effects on demographic rates, which may affect a species' resilience, defined as a persistence of a population despite perturbations (sensu Holling 1973). Research suggests a degree of plasticity in vital rates, e.g. size at maturity, fecundity (which may be a function of environmental factors), population density, and age structure; these factors may be particularly important in populations that are recovering from perturbations, in which population density and age structure are changing rapidly (Gotthard \& Nylin 1995, Kuparinen \& Merila 2007). In turn, populationlevel changes in demographic rates may affect the ability of species to recover. For example, in several populations of Atlantic cod Gadus morhua, fisheriesinduced changes to mean size and age at maturity have likely decreased the ability of this species to recover from overfishing (Hutchings 1996, 2000, Hutchings \& Reynolds 2004). Conversely, as abundance increases and age structure is restored, demographic rates may return to pre-disturbance levels (Conover et al. 2009). Studies of demographic rate changes in the context of population depletion or recovery suggest that shifts in mean growth, survival, or reproduction are important to consider in modeling exercises to evaluate future trends and response to management (Rochet 2000a,b, Gerber \& Heppell 2004, Thorson et al. 2015).

We hypothesize that once populations are in the process of recovery, changes in demographic rates or life-history traits may also give an indication of the status of the population, hereafter referred to as demographic indicators (DIs). However, we must first understand how DIs and their variability are linked to abundance. If a DI displays a trend in response to decline or recovery, then the DI can be linked to population abundance, and once general relationships are established, a DI could be used as a population status indicator in the absence of a population index (Bjorndal et al. 2000, Sæther \& Bakke 2000, Caut et al. 2006, Hutchings et al. 2012). Conversely, if a DI has high interannual variability but no significant trend, the variability itself could affect population growth, abundance, and recovery rates, and is valuable information in itself (Mazaris \& Matsinos 2006, Bjorndal et al. 2010). Further, the timeframe in which DIs are estimated in relation to the status of the species (e.g. prior to exploitation, during, or post-exploitation) can have important ramifications for population assessments, especially if temporal variability is not accounted for in the estimation process. For longlived species with long generation times, it is also important to account for time lags in changes to DIs. For example, in a study of Kemp's ridley sea turtles Lepidochelys kempi, Heppell et al. (1996) found that recovery times depend on age at maturity, as newly protected age classes recruit into the adult population. Population models usually must rely on estimates of DIs from the literature, which often come from historic references, taken at times that no longer directly pertain to the current population. This imprecision of DI estimates can have important implications for accurately estimating abundance and population growth, and forecasting short-term and long-term trends, even though temporal variability in DIs is rarely measured in sea turtle studies (Bjorndal et al. 2010, Richards et al. 2011).

To understand how DIs vary over time and in relation to abundance of a long-lived species, we examined a well-studied population of green sea turtles in Hawaii (USA). A recent National Research Council report emphasized that monitoring the numbers of nesters or nests is insufficient to diagnose changes in population size (Bjorndal et al. 2010). Rather than focusing on indices of abundance, Bjorndal et al. (2010) recommended research toward quantifying changes and variability in key DIs to better understand the relationship with DIs and population abundance and population growth. Looking to the future, many sea turtle monitoring programs may not be able to continue indefinitely or may not be able to supply the work force to keep pace with the size of recovering populations (and maintain sufficient detection probabilities). Examining DIs may be one solution and could complement monitoring index nesting beaches, especially as changes in DIs may give important context to observed changes in abundance on nesting beaches.

Green sea turtles are listed as a threatened species under the US Endangered Species Act (ESA) throughout the USA, but populations in the Mediterranean, Central West Pacific, and Central South Pacific continue to be endangered (NOAA \& USFWS 2015). The Hawaiian population has experienced remarkable recovery in the last 2 decades with an estimated $5.4 \% \mathrm{yr}^{-1}$ increase in the nesting population since 1973 (see Fig. 1; Chaloupka et al. 2008, Balazs et al. 2015). Population recovery is primarily attributed to elimination of hunting pressure for juvenile and adult sea turtles in the Hawaiian Islands (Balazs \& 
Chaloupka 2004b). Intensive monitoring of this recovering population and its relative geographic isolation make it an excellent case study for examination of temporal variability in DIs.

Because of fisheries management and conservation measures, it is also likely that vital rates of green turtles in Hawaii have changed over time, in the absence of hunting pressure and in response to changes in population density (Gotthard \& Nylin 1995, Hutchings 1996, 2000, Hutchings \& Reynolds 2004, Conover et al. 2009). Existing estimates of the number of years females spend between nesting (remigration interval) and mean body size of Hawaiian green sea turtles do not account for changes in the vital rates, even though data collection began in the 1970s, when harvest was still permitted (Balazs 1980, Balazs et al. 2015). In addition, some of these estimates were taken from short-term field studies, with relatively small sample sizes of females (Balazs 1980, Van Buskirk \& Crowder 1994). Adult female annual survival rate for Hawaiian green turtles was recently estimated using matrix projection models and Monte Carlo techniques for optimization, but survival rate was not evaluated for temporal variability, nor was uncertainty estimated (Van Houtan et al. 2014).

We hypothesize that DIs will be different today than when the population was at very low density. Protection of the neritic, or near-shore, life stages from harvest should result in high annual survival and strong recruitment of new nesters each year (Campbell \& Lagueux 2005, Troëng \& Chaloupka 2007). As the population grows and approaches carrying capacity, the remigration interval should lengthen as greater intraspecific competition for resources makes it harder for females to build up physiological stores for egg-laying (Miller 1997, Troeng \& Chaloupka 2007). During recovery, as age structure is restored, it is likely that mean nester size and size at maturity will decrease as new cohorts recruit into the adult population (Crowder et al. 1994).

To address the issue of temporal variability in DIs and their relationship with abundance and population recovery, we asked 3 questions: (1) Do the DIs (annual survival rate, annual breeding probability, nester carapace length, and size at maturity) show temporal trends and fluctuations? (2) If so, are the DIs correlated with nester abundance? (3) Which of these measures could serve as a good indicator of population size and status (i.e. increasing, decreasing, or stable over time), given that we have strong evidence that this population is recovering? Using a $38 \mathrm{yr}$ mark-recapture data set from the principal nesting ground, we evaluated these questions for a population that has grown more than an order of magnitude, from about 35 nesting females to nearly 600 .

\section{MATERIALS AND METHODS}

\section{Study population}

Green sea turtles in Hawaii were recently categorized as a distinct population segment based on mitochondrial DNA, anatomical features, and migratory patterns (Dutton et al. 2008, NOAA \& USFWS 2015). There is little gene flow between Hawaii and other populations throughout the Pacific Ocean. The vast majority of nesting takes place in the Northwestern Hawaiian Islands (NWHI), and the largest rookery is at East Island, French Frigate Shoals, where approximately $50 \%$ of Hawaiian nesting occurs, and where continuous monitoring has occurred since 1973 (Balazs 1980, Balazs \& Chaloupka 2004b). East Island is a small sandy atoll, $\sim 0.036 \mathrm{~km}^{2}$, surrounded by a shallow lagoon on the western side and a fairly steep shelf on the eastern side. Generally, nesting site fidelity at French Frigate Shoals is high (>95\%; Balazs 1980, Dizon \& Balazs 1982, Bowen et al. 1992). Females generally will not nest in the year immediately following a nesting year (i.e. obligate skipnesting) and vary in the number of years between nesting migrations. The length of the remigration interval depends on energetics, physiology, and environmental conditions (Chaloupka \& Limpus 1996, Limpus \& Chaloupka 1997, Miller 1997, Solow et al. 2002). Within a nesting season, Hawaiian green turtles will return several times to lay an average of 4 clutches at approximately 2 wk intervals (Balazs 1980, Tiwari et al. 2010), so the probability of sighting an individual turtle at least once during a season in which she breeds is high.

Historically, green sea turtles were abundant and nested throughout the entire Hawaiian Islands chain (Kittinger et al. 2013). Nesting contracted to the NWHI sometime in recent history, but prior to modern scientific records (as late as the early 1950s in some cases), and was most likely due initially to subsistence harvest of sea turtles and then later by more intensive commercial harvest (Balazs 1980, Witzell 1994, Kittinger et al. 2013). Generally, nesting in the NWHI was naturally protected by its remoteness from permanent human settlements; however, intermittent harvest from ships passing through the area and by the military probably occurred, and egg harvest was extremely limited before protection, unlike 
many other sea turtle rookeries globally (Balazs 1980, Mast et al. 2011). Sea turtle harvest was tightly regulated by the 'kapu' system, or code of conduct, of native Hawaiians, but after European colonization, around 1819, this system began to erode (Balazs 1980). In the 20th century, numbers of green sea turtles dropped precipitously as harvest intensified and became more commercialized in the Hawaiian Islands (Balazs 1980, Witzell 1994, Van Houtan \& Kittinger 2014). Fishermen often selected juveniles, sub-adults, and smaller adults for harvest, and shifted towards larger animals as fishing trips moved offshore towards the end of the fishery (Balazs 1980, Witzell 1994, Kittinger et al. 2013, Van Houtan \& Kittinger 2014). In 1978, green sea turtles were placed on the US Endangered Species List and harvest was prohibited (NOAA Office of Protected Resources 2014).

\section{Data description}

Globally, the Hawaiian green sea turtle nesting population experienced one of the most continuous and consistent monitoring efforts. We used data from the NOAA Pacific Islands Fisheries Science Center Turtle Research Program (TRP). Nesting at East Island was monitored annually, during the summer months, since 1973, first by G. Balazs and the Hawaii Institute of Marine Biology and then by NOAA Fisheries and the US Fish and Wildlife Service from 1981 onward (Nurzia Humburg \& Balazs 2014). Data collection was conducted under approved State of Hawaii and US Federal permits. Survey effort and duration varied annually depending on a number of logistical factors (Balazs \& Chaloupka 2004b), and ranged from 9 (1977) to 143 (1989) nights. Females that emerged to nest were individually marked with flipper tags, etched with an electric drill, and painted for easy reidentification at a distance during the rest of the nesting season. Double-tagging with passively integrated transponder (PIT) tags was instituted in 1996 to improve individual turtle identification, as flipper tags can be lost. When encountered, turtles were checked for existing tags, carapace length was measured, and nesting behavior was noted (e.g. body pit excavation, egg laying, covering nest burial). The TRP maintains a tag database of all turtles encountered on the nesting beach. Previous evaluation of the nesting beach data during a period of extended intensive survey (1988-1992) suggests that 56 to $66 \%$ of nesting females identified each year were newly tagged (Nurzia Humburg \& Balazs 2014). However, in years where sampling did not cover the entire nesting sea- son, it is possible that some nesters, particularly those females who started nesting early or late in the season (since sampling strives to cover the mid-point of the nesting season), were not captured during their first nesting season and would not be tagged until a return nesting migration.

\section{Temporal analysis of demographic indicators}

Size at maturity

Newly tagged turtles may represent neophyte (first season) nesters, and size at first tagging likely represents the minimum size at maturity for those animals (Richardson et al. 2006), given the history of nesting season surveys. In using this approach, we assumed that these newly tagged nesters (nominal neophytes) have not nested in previous seasons or on other unmonitored islands in Hawaii. We used 1981 as our first year of analysis, because it was the first year in which the percentage of newly tagged turtles stopped increasing, following a high percentage in the early years when the monitoring program first started, after the initial tagging effort (Nurzia Humburg \& Balazs 2014). We plotted the straight carapace length $\left(\mathrm{SCL}_{i} \mathrm{~cm}\right)$ of newly tagged turtles (i.e. nominal neophytes) and veteran turtles (turtles with tags or tag scars) across years to determine whether there were differences in carapace lengths between the 2 groups. If an individual was measured multiple times within a season, we took the average of the measurements, as it is unlikely that adult sea turtles would grow appreciably within a nesting season. We tested the fit of the residual SCLs to a normal distribution and found no significant departure from that distribution. We then statistically tested for differences using linear mixed models (LMMs) with a restricted maximum likelihood estimator, and accounted for the temporal autocorrelation within individuals, and across years, using a specified covariance structure (e.g. AR(1), Toeplitz, compound symmetry etc.), in SAS 9.3. LMMs are advantageous compared to other statistical methods in that they can take advantage of repeated measurements across individuals, account for the intrinsic autocorrelation of repeated measures, and correctly characterize the variance associated with the estimated parameters (Littell et al. 1998, Bolker et al. 2009). The candidate model set included an intercept-only null model, a categorical year effect, a tagging effect (tagged or untagged), or year and tagging effects. We tested various covariance structures for temporal autocorrelation of indi- 
vidual turtles, and compound symmetry had the best model fit to the data.

\section{Carapace length distributions}

To test for differences in carapace length over time, we estimated the mean SCL of nesters each year using LMM with a restricted maximum likelihood estimator, in SAS 9.3. We followed the same modeling routine as with size at maturity. We tested various covariance structures for temporal autocorrelation of individual turtles, and compound symmetry had the best model fit to the data. The candidate model set included an intercept-only null model, and a categorical year effect, along with the tested covariance structures.

Survival and reproduction vital rates: mark and recapture-based models

We used a multi-state open robust design model (MSORD), with an unobservable state, to estimate adult female survival rate $(S)$, the transition probabilities of moving from nesting to foraging states and from foraging (unobservable) to nesting $\left(\psi_{\mathrm{N} \rightarrow \mathrm{F}}\right.$ and $\psi_{\mathrm{F} \rightarrow \mathrm{N}}$, respectively), detection probability $(p)$, probability of entering the nesting state $\left(p_{\text {ent }}\right)$, and the probability of remaining in the nesting state $(\varphi)$, using maximum likelihood in Program Mark, version 7.1 (Pollock 1982, Kendall \& Bjorkland 2001, Kendall \& Nichols 2002, Cooch \& White 2013, Kendall 2013). The MSORD model accounts for sampling error and confounding between mortality and non-detection (Kendall \& Nichols 2002, Kendall 2013). The robust design provides secondary within-season information, which improves parameter estimation and precision (Kendall \& Nichols 2002). Open robust design models permit the relaxation of 2 assumptions of closed populations: the population is closed to additions and deletions within a primary season, and each member of the population has an equal probability of being available for detection in a given time period (Kendall \& Bjorkland 2001). Following the approach of Kendall \& Bjorkland (2001), we divided the nesting survey season into $14 \mathrm{~d}$ periods, because the average inter-nesting interval for green sea turtles in Hawaii is $13.4 \mathrm{~d}$ (range: 11-18 d) and this was the optimal period after preliminary iterative testing of the interval length (Balazs 1980, Kendall \& Bjorkland 2001). The total number of within-season survey periods varied annually depending on the total num- ber of survey nights in a primary season. The parameters were modeled as time-varying or constant for each primary (year) and secondary (14 d) period. Survival for nesters and non-nesters was assumed to be equal. For the unobservable state (foraging state), $p_{\text {ent }} \varphi$, and $p$ are set to 0 . For models with full timedependence in detection probability $\left(p_{t t}\right)$, it is necessary to set the final year equal to the previous year (e.g. $\left.p_{2008,1}=p_{2009,1}\right)$ to avoid issues with parameter estimation (Kendall 2013). We modeled within-season temporal effects on $p_{\text {ent }}$ as a multinomial distribution so that within secondary periods, $p_{\text {ent }}$ summed to 1 . We were only able to run these models for 1981 to 2009, as 1973 to 1980 and 2010 did not have large enough sample sizes or long enough primary seasons for the models to converge.

The transition probability $\psi_{\mathrm{F} \rightarrow \mathrm{N}}$ may be used as an estimate of annual breeding probability, as only females observed on the nesting beach in the process of nesting (e.g. egg laying, nest burial, complete crawls up to nest and back to the water etc.) were included in the dataset (Kendall \& Bjorkland 2001). Since many turtles bask on East Island, and potentially could give a false positive of nesting, thereby ultimately yielding a biased estimate of breeding probability, we only included confirmed nesting events in the dataset. With this model structure, we were also able to test for random transition probabilities, where the probability of transitioning from a nester to forager equaled the probability of transitioning from forager to nester $\left(\psi_{\mathrm{N} \rightarrow \mathrm{F}}=\psi_{\mathrm{F} \rightarrow \mathrm{N}}\right)$, and Markovian transition probabilities, where the probability of transitioning from nester to forager does not equal the probability of transitioning from forager to nester $\left(\psi_{\mathrm{N} \rightarrow \mathrm{F}} \neq \psi_{\mathrm{F} \rightarrow \mathrm{N}}\right)$, and this ultimately tests the occurrence of obligate skip-nesting (Kendall \& Bjorkland 2001, Kendall 2013). Typically, breeding frequency for sea turtles is calculated as

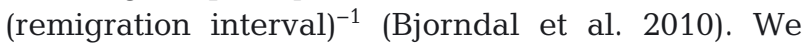
back-calculated remigration interval as $1+\left(\psi_{\mathrm{F} \rightarrow \mathrm{N}}\right)^{-1}$. If annual breeding probability is the probability of becoming a nester when an individual was a skip nester in year $t-1$, then it is necessary to add 1 year to $\left(\psi_{\mathrm{F} \rightarrow \mathrm{N}}\right)^{-1}$ to account for the additional year it would take to go from nester to forager (as green sea turtles are obligate skip nesters).

It is also possible to derive clutch frequency from the tagging data using the MSORD model, based on the residence time of sea turtles in the nesting state. However, we did not include it here because of a strong bias with the number of secondary sampling periods, where years with fewer secondary periods had a lower estimate of clutch frequency (see the Supplement ['Estimating clutch frequency using MSORD 
models'] at www.int-res.com/articles/suppl/n031p103_ supp.pdf for more information).

We tested the hypothesis that temporal variation was important in the estimation of the DIs by determining whether a model containing temporal effects on survival and breeding probability was top-ranked based on Akaike's information criterion corrected for small sample sizes (AICc). First, we tested a variety of models with temporal effects within and across seasons for the parameters $p, p_{\text {ent }}$ and $\varphi$, and assumed temporal effects across and within seasons for adult annual survival $(S)$, the probabilities of transitioning from nester to forager, and forager to nester $\left(\psi_{\mathrm{N} \rightarrow \mathrm{F}}\right.$, and $\psi_{\mathrm{F} \rightarrow \mathrm{N}}$, respectively). Using the best-fitting model, we then tested for temporal effects of $S$ and $\psi$, and whether $\psi_{\mathrm{N} \rightarrow \mathrm{F}}=\psi_{\mathrm{F} \rightarrow \mathrm{N}}$. In addition, we explored different parameterizations of $\psi$, using the initial second ranked model as well.

Currently, no standardized goodness-of-fit test exists for MSORD models, although some experimental methods have been tested. As an alternative, we ran a median $\hat{C}$ test (Cooch \& White 2013) on a simplified multistate fully time-dependent model (with nesters and unobservable foragers, but no robust design), and found that $\hat{c}=1.489$ (95\% CI: 1.466-1.513). Previous research indicates $\hat{C} \leq 3.0$ is acceptable and suggests a reasonable fit of the model to the data (Lebreton et al. 1992).

\section{Model selection procedures}

For all analyses, we compared models with and without a year effect to test for temporal trends in DIs. Model selection was based on AICC and the information-theoretic approach to select the most parsimonious model of the candidate model set (Burnham \& Anderson 2002). In the informationtheoretic approach, candidate models represent biological hypotheses, and are tested via the degree of quantitative support, i.e. model likelihoods and AICc (Burnham \& Anderson 2002, Johnson \& Omland 2004). Model selection is preferred to traditional null hypothesis testing for observational data, where no explicit experimental framework is imposed or when multiple models have the potential for similar levels of support (Anderson et al. 2000, Burnham \& Anderson 2002, Johnson \& Omland 2004). We compared the top model to an intercept-only model that represented the null model, and used evidence ratios to assess the strength of evidence for the top-ranked model (Anderson et al. 2000). Evidence ratios ( $\rho$ ) are cal- culated by dividing the AICc weight of the model containing the term under consideration $\left(w_{i}\right)$ by the AICc weight of the model when the term is removed $\left(w_{j}\right)$. The greater $\rho$, the more important the explanatory variable of interest is as a predictor in the model.

\section{Nester abundance estimation}

Estimates of nester abundance were extrapolated from raw counts of observed individuals to account for observer error, e.g. non-detection of nesters, and because monitoring usually did not cover the entire nesting season, except for a period of saturation tagging in 1988 to 1992. We used estimates of nester abundance derived from a model by Wetherall et al. (1998) in our analysis (Fig. 1). Wetherall et al. (1998) developed a method using a Horvitz-Thompson type estimator to estimate the number of nesters based on the number of survey nights in a given season, and using the covariates of arrival time, nesting frequency, nesting duration, and inter-nesting interval (see also Balazs \& Chaloupka 2004b). Their sighting probability function was calibrated using the entire nesting season census derived from nightly emergence probabilities during a 5 yr period of saturation tagging (1988-1992; Wetherall et al. 1998). Confidence intervals were derived using an empirical bootstrap approach for each annual estimate. We used this ap-

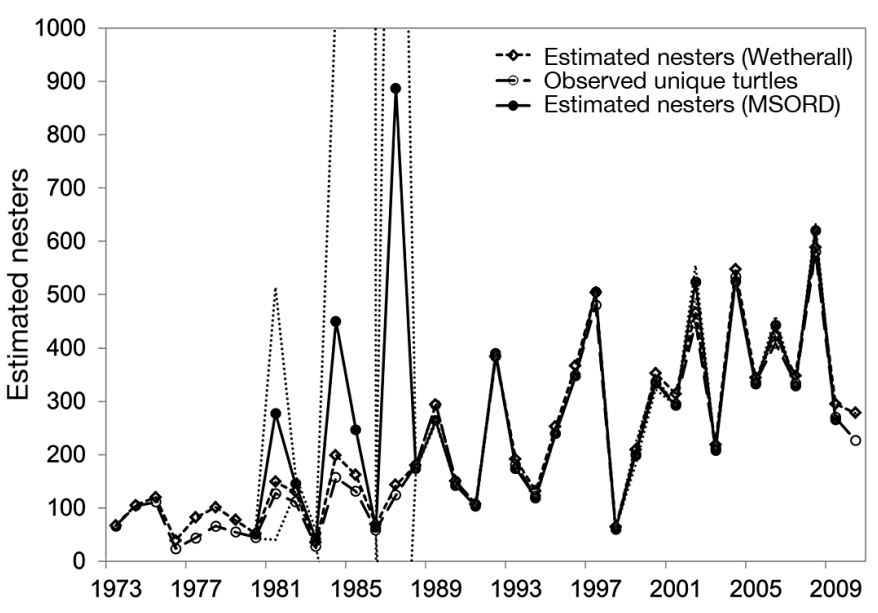

Fig. 1. Abundance of nesting green sea turtles Chelonia mydas at East Island, French Frigate Shoals, Hawaii, USA, based on counts of observed individual turtles, the estimated total number of nesters (using the method of Wetherall et al. 1998), and the estimated total number of nesters using the top-ranked multistate open robust design model (MSORD) at East Island, 1973 to 2010. Dotted lines indicate $95 \%$ confidence intervals around the estimated number of nesters. Extreme values for the $95 \%$ confidence intervals in some years were left off for better visualization of the data 
proach as it was an independent method to estimate nester abundance, rather than the abundance estimates derived from the MSORD approach, which uses the estimates of $\psi_{\mathrm{F} \rightarrow \mathrm{N}}$ (i.e. breeding probability) in the calculation.

\section{Demographic indicators and nester abundance}

If the top-ranked model included a temporal effect on a DI, we tested for a relationship between the annual estimate of the demographic indicator and the estimated nester abundance for the given year. We used generalized linear models (GLMs) to test for relationships between $\ln$ (nester abundance) and the DIs in R (version 3.0.1) with the packages car, MASS, gvlma, and MuMIn. We modeled SCL with a Gaussian distribution, and all assumptions of a linear model were met based on tests of skewness, kurtosis, and heteroscedasticity. Breeding probability was best fit by using a gamma distribution. We compared the models with and without $\ln$ (nester abundance), i.e. intercept-only, using evidence ratios, to test our hypothesis that nester abundance and the DIs are related (Burnham \& Anderson 2002).

\section{RESULTS}

\section{Size at maturity}

A total of 3277 individual turtles were examined for differences in the mean carapace length of nominal neophyte and veteran nesters, with 6773 total observations (with repeated measurements on turtles across years). Substantial overlap existed in the size distributions for the 2 groups for all years (Fig. 2). However, we found that the model which included the tagging effect and a categorical year effect, along with a compound symmetry covariance structure to account for temporal autocorrelation within individual turtles, was orders of magnitude more likely than the null model (Table 1). While the top-ranked model included tagging status as a predictor (i.e. newly tagged or veteran nester), the magnitude of the difference was small: the estimated range of the yearly means of SCL for newly tagged turtles was $89.3 \mathrm{~cm}$ (95\% CI: $88.8-89.8 \mathrm{~cm})$ to $91.2 \mathrm{~cm}(95 \% \mathrm{CI}: 90.9-$ $91.7 \mathrm{~cm}$ ) and the range for veteran turtles was $89.8 \mathrm{~cm}$ (95\% CI: 89.3-90.3 cm) to $91.7 \mathrm{~cm}(95 \%$ CI: $91.3-$ $92.2 \mathrm{~cm}$; Fig. 3; see Table S1 in the Supplement at www.int-res.com/articles/suppl/n031p103_supp.pdf). This amounts to roughly $0.5 \mathrm{~cm}$ difference in cara-

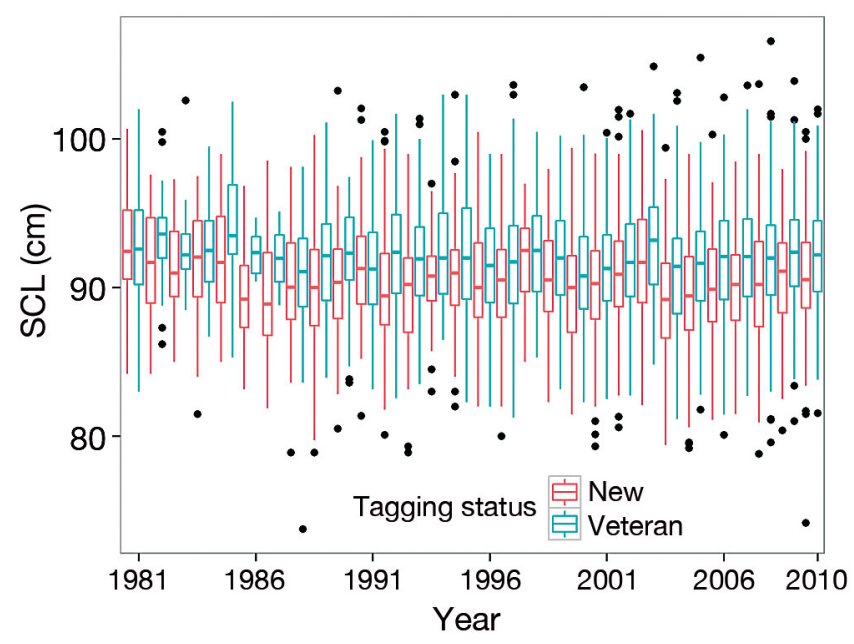

Fig. 2. Straight carapace length $(\mathrm{cm})$ of newly tagged and veteran green sea turtle Chelonia mydas nesters from 1981 to 2010 at East Island, French Frigate Shoals, Hawaii, USA. The years 1973 to 1980 were excluded to account for untagged veteran nesters. Whiskers indicate 1.5 inter-quartile range, midlines indicate medians, and black dots indicate outliers

pace length between newly tagged and veteran nesters each year, which falls within measurement error. As such a small difference in carapace length between nominal neophyte and veteran nesters exists, we did not distinguish neophytes and veterans for the rest of the analysis.

\section{Temporal analysis of carapace length}

Year was an important predictor of carapace length, based on the top-ranked model, which included annual estimates of carapace length, and a compound symmetry covariance structure to account for temporal autocorrelation within individual turtles. A total of 3677 individual turtles were included, with 7348 total

Table 1. Calculation of evidence ratio $(\rho)$ for straight carapace length (SCL) during the years 1981 to 2010 as a function of tagging status (newly tagged or veteran nester) and year compared to a model without tagging status. Evidence ratios are calculated as the ratio of the Akaike's information criterion corrected for small sample size (AICc) weight of the best model with and without the variable of interest

\begin{tabular}{|cc|}
\hline Calculation & SCL 1981-2010 \\
\hline $\begin{array}{l}\text { AICc weight for best model with } \\
\text { tagging status effects, } w_{i}\end{array}$ & 1.000 \\
$\begin{array}{l}\text { AICc weight for best model without } \\
\text { tagging status effect, } w_{j}\end{array}$ & $2.12 \times 10^{-233}$ \\
Evidence ratio $\left(w_{i} / w_{j}\right)$ & $4.713 \times 10^{232}$ \\
\hline
\end{tabular}




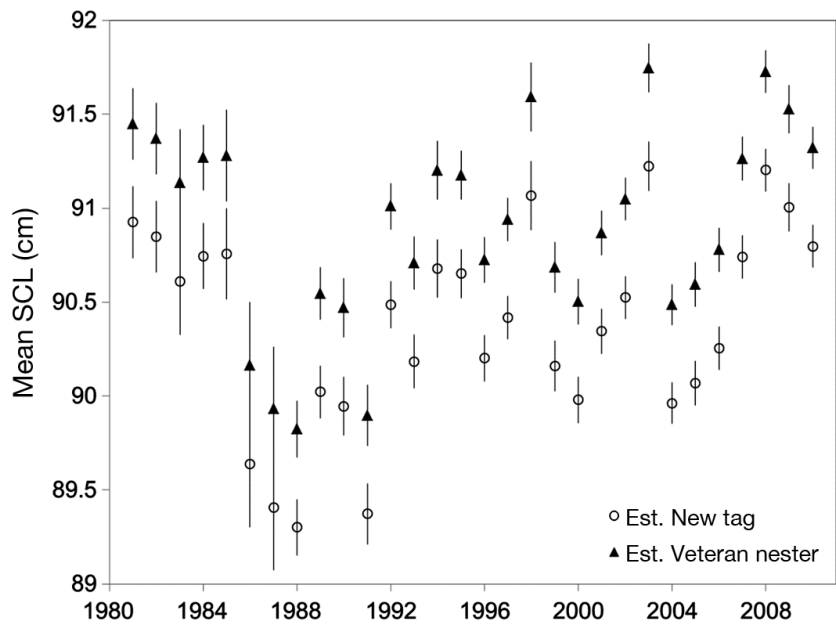

Fig. 3. Linear mixed model estimates of mean $( \pm \mathrm{SE})$ straight carapace length (SCL, cm) of newly tagged and veteran green sea turtle Chelonia mydas nesters at East Island, Hawaii, USA, 1981 to 2010. The years 1973 to 1980 were excluded to account for untagged veteran nesters

observations (with repeated measurements on individual turtles across years). Mean carapace length varied from 1973 to 2010, and the model estimates of mean SCL ranged from $89.21 \mathrm{~cm}$ (95\% CI: 88.97$89.46 \mathrm{~cm})$ in 1988 to $91.69 \mathrm{~cm} \mathrm{(95 \%} \mathrm{CI:} \mathrm{91.50-}$ $91.8 \mathrm{~cm}$ ) in 2008 (Table 2, Fig. 4A). While the topranked model included year as an important predic- tor of SCL, there was no strong directional trend in the estimates of SCL over the entire time-series, but short-term trends of increasing SCL over several years followed by steep declines in SCL were apparent (Fig. 4A). Moreover, more general longer-term trends $(\sim 10 \mathrm{yr})$ were apparent; after a period of declining SCL (1977-1989), turtle lengths began to increase.

\section{Mark-recapture modeling of DIs}

Temporal variation figured prominently in the topranking MSORD model used to estimate annual survival rate, breeding probability, probability of entering the nesting state, probability of remaining in the nesting state, and detection probability. The topranking model included a full model weight of 0.999 and model likelihood of 1 (Table 3). A total of 3405 individual turtles were included in the encounter histories, and 2678 turtles were recaptured at least once. The top-ranking model did not include temporal variation in annual adult female survival $\left(S=0.929 \mathrm{yr}^{-1}\right.$, $95 \%$ CI: 0.924-0.933 $\mathrm{yr}^{-1}$; Table 2).

Breeding probability, or the probability of transitioning from foraging to nesting, was estimated annually in the top-ranking model. Annual breeding probability ranged from 0.0766 (95\% CI: 0.0574-0.102) in

Table 2. Published estimates of demographic indicators and estimates from this analysis for Hawaiian green sea turtles Chelonia mydas. For the published value, we provide values given from multiple studies if they exist. The order of the references corresponds to the order in the published value column. SCL: straight carapace length, $\psi_{\mathrm{F} \rightarrow \mathrm{N}}$ : transition probability between the 2 states, nester $(\mathrm{N})$ and forager $(\mathrm{F}), P_{\text {ent }}=$ probability of entering nesting state, $\varphi=$ probability of remaining in nesting state, $p=$ detection probability, na: not available. See the Supplement at www.int-res.com/articles/suppl/n031p103_ supp.pdf for a discussion of clutch frequency analysis

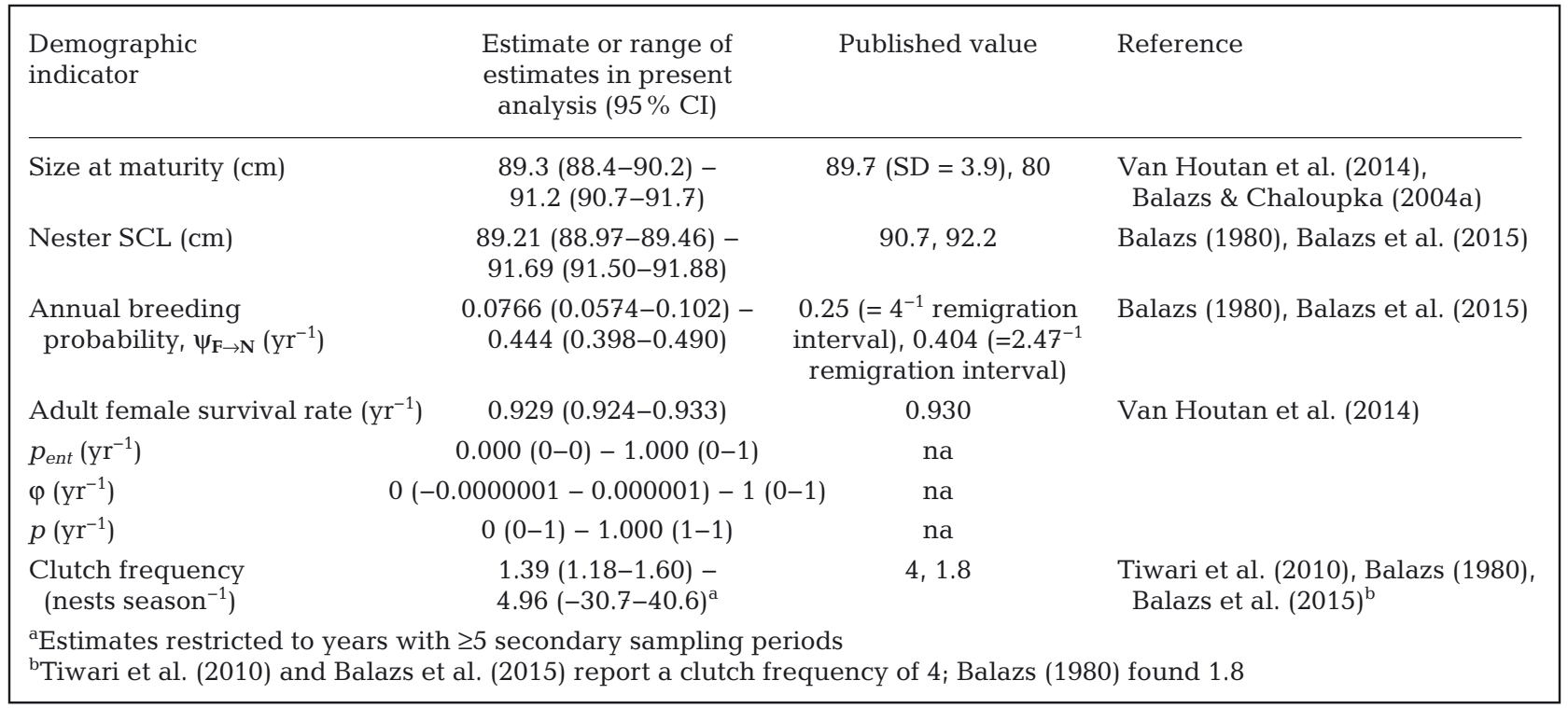



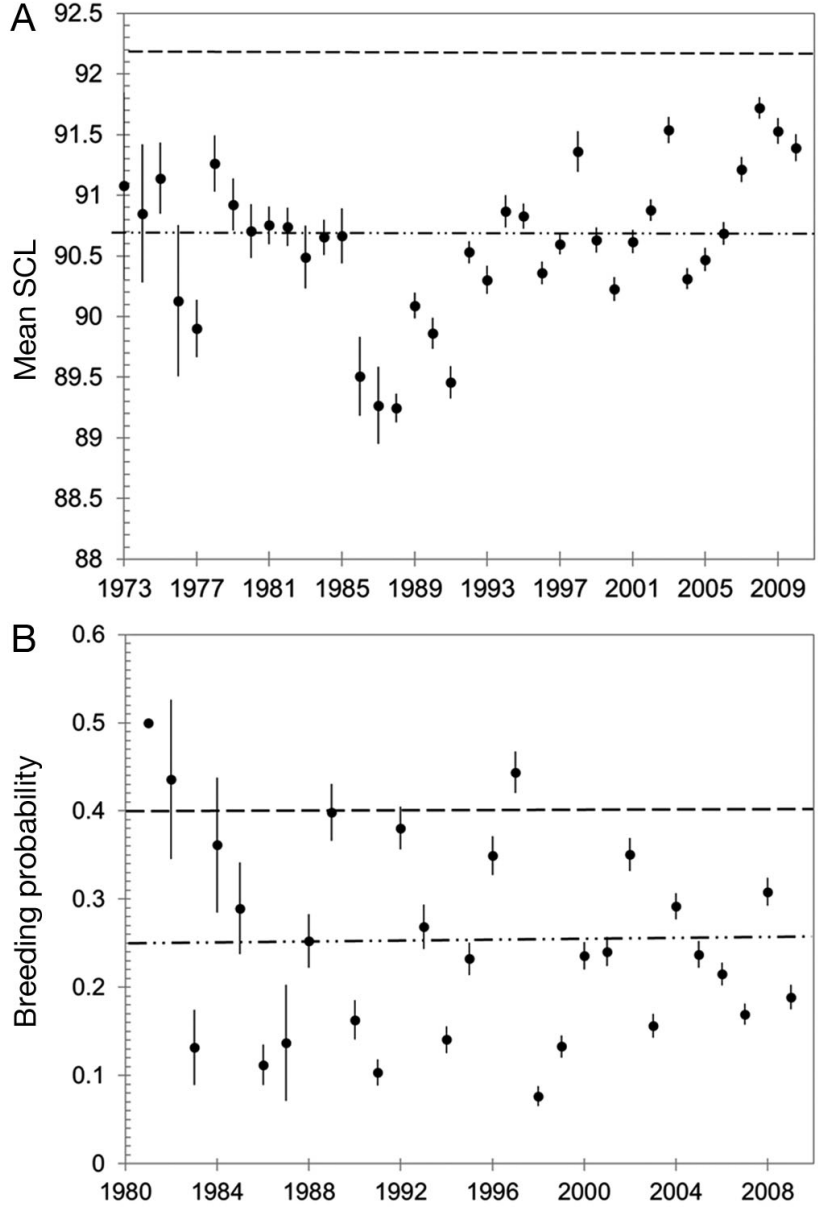

Fig. 4. Annual estimates of demographic indicators $( \pm \mathrm{SE})$ : (A) mean straight carapace length $(\mathrm{SCL}, \mathrm{cm})$ of green sea turtle Chelonia mydas nesters based on linear mixed models (LMMs) from 1973 to 2010 and (B) mean breeding probability $\left(\mathrm{yr}^{-1}\right)$ based on multistate open robust design models (MSORD) from 1980 to 2009. Remigration interval (years between nesting seasons) equals (breeding probability $)^{-1}+1$ (see 'Materials and methods: Survival and reproduction vital rates'). Dashed lines refer to the published historical estimates, and the dot-dash line represents the recent constant estimates of Balazs et al. (2015) of the demographic indicators
1998 to 0.444 (95\% CI: 0.398-0.490) in 1997 (Table 2, Fig. 4B). If these probabilities were constant for individuals, they would correspond to remigration intervals of 3.3 to $14.1 \mathrm{yr}$. The top-ranked model included year as an important predictor of breeding probability, but there was no strong linear trend over the whole time series, although there were short-term trends of increasing breeding probabilities, followed by steep drop-offs (Fig. 4B). The strong cyclic pattern appears to dampen in later years of the time series, but additional years of data are needed to verify this.

The top-ranking model also included a constant estimate of transition probability of nesters moving to the foraging state, 0.989 (95\% CI: 0.925-0.998). This result corroborates a wide body of previous research that nearly all individual females will skip-nest the year immediately following nesting, and take at least $2 \mathrm{yr}$ to return to the nesting beach, and likely much longer on average (Miller 1997, and references therein).

For detection probability, the top-ranking model included temporal estimates for both within- and acrossseason effects (Table 3). The range of estimates for detection probability was 0 (95\% CI: $0-1)$ to 1 (95\% CI: $0-1)$, e.g. $p=0$ in the third secondary sampling period in 1982, and $p=1$ in the first secondary sampling period of 1984 (Table 2). Notably, the MSORD models can have difficulty in estimating parameters and the uncertainty of those estimates when estimates are close to their boundaries of 0 or 1 (Kendall 2013). In general, detection also varied across secondary periods within primary periods (years). For example, in 2008, detection ranged from $p_{2008,4}=0.147$ (95\% CI: $0.118-$ 0.0183 ) to $p_{2008,2}=0.970$ (95\% CI: $\left.0.947-0.983\right)$, where subscripts indicate the year and 2 wk within-season secondary periods. During the years of saturation tagging, 1988 to 1992, detection probabilities were higher, and ranged from 0.59 (95\% CI: $0.39-0.76)$ to 1.00 (95\% CI: 0-1).

Table 3. Akaike's information criterion corrected for small sample size (AICc) for the 5 highest ranking models fit to capturerecapture data collected from breeding green sea turtles Chelonia mydas at East Island, French Frigate Shoals, Hawaii, USA, 1980 to 2009. $S$ : survival rate, $\psi$ : transition probabilities between the 2 states, nester $(\mathrm{N})$ and forager $(\mathrm{F}), p_{\text {ent }}$ : probability of entering the nesting population, $\varphi$ : probability of remaining in the nesting population during a secondary sampling period, $p$ : detection probability, and $L$ : likelihood. Survival for nesters and foragers is assumed to be equal. For the unobservable state (foraging), $p_{\text {ent }}, \varphi$, and $p$ are set to 0 . Constant: constant estimate over time, Time: separate estimate for each time period, $1^{0}$ : single estimate per primary period, and $2^{0}$ : single estimate per secondary period. \# Par: number of parameters included in model, $\triangle \mathrm{AIC}$ : the difference in Akaike information criteria corrected between the top ranked model and the model under consideration. AICc weight indicates the relative support and fit of each model

\begin{tabular}{|lllllllllll|}
\hline Model & $S$ & \multirow{2}{*}{$\psi_{\mathrm{N} \rightarrow \mathrm{F}}$} & $\psi_{\mathrm{F} \rightarrow \mathrm{N}}$ & $p_{\mathrm{ent}}$ & $\varphi$ & $p$ & \# Par & $\Delta$ AICc & AICc weight & Model $L$ \\
\hline 1 & Constant & Constant & Time & Time & Time & Time & 309 & 0 & 0.99999 & 1 \\
2 & Constant & Time & Time & Time & Time & Time & 335 & 23.8029 & 0.00001 & 0 \\
3 & Time & Time & Time & Time & $2^{0}$ & Time & 311 & 69.9503 & 0 & 0 \\
4 & Constant & Constant & Time & $1^{0}$ & Time & Time & 231 & 129.0565 & 0 & 0 \\
5 & Constant & Time & Time & $1^{0}$ & Time & Time & 259 & 182.9021 & 0 & 0 \\
\hline
\end{tabular}


Table 4. Evidence ratios ( $\rho$ ) calculated separately for 2 demographic indicators (DI; mean straight carapace length [SCL] and breeding probability) as a function of green sea turtle Chelonia mydas nester abundance compared to a simple model without temporal variation. Evidence ratios are calculated as the ratio of the Akaike's information criterion corrected for small sample sizes (AICc) weight of the best model with and without the variable of interest

\begin{tabular}{|lcc|}
\hline Calculation & $\begin{array}{c}\text { Mean } \\
\text { SCL }\end{array}$ & $\begin{array}{c}\text { Breeding } \\
\text { probability } \\
\left(\psi_{\mathrm{F} \rightarrow \mathrm{N}}\right)\end{array}$ \\
\hline $\begin{array}{l}\text { AICc weight for best model } \\
\text { with temporal effect of DI, } w_{i}\end{array}$ & 0.562 & 0.999 \\
$\begin{array}{l}\text { AICc weight for best model } \\
\text { without temporal effect of DI, } w_{j} \\
\text { Evidence ratio }\left(w_{i} / w_{j}\right)\end{array}$ & 0.817 & 0.0808 \\
\hline
\end{tabular}

\section{DIs as a function of nester abundance}

We did not find a strong relationship between mean SCL and nester abundance. The intercept-only model was selected over the models with temporal variation of SCL (Table 4). We did not evaluate annual survival because the top-ranking model did not include temporal estimates of survival.

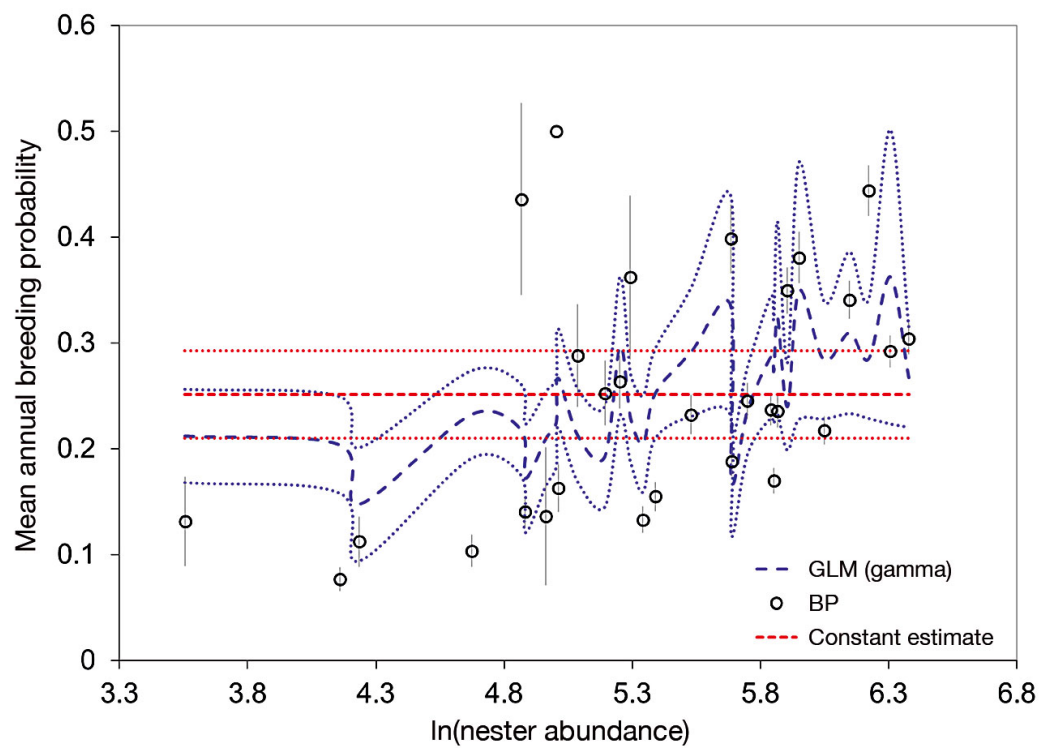

Fig. 5. Relationship between ln-transformed estimate of green sea turtle Chelonia mydas nester abundance (based on an estimation model developed by Wetherall et al. 1998) and annual breeding probability ( \pm SE). The predicted values of breeding probability (BP) are based on a generalized linear model (GLM) with a gamma distribution (blue dashed line) and $95 \%$ CI (blue dotted line). The red dashed line indicates the regression line for an interceptonly model (which represents the null model where there is no relationship

between the BP and nester abundance) and 95\% CI (red dotted lines)
Nester abundance was a good predictor of breeding probability; the probability of breeding increased with an increasing nester population (Fig. 5). Model selection of the regression between nester abundance and the breeding probability ranked the model with temporal estimates of breeding probability over an intercept-only model (no difference across years). The model with annual estimates of breeding probability was 12 times more likely than the interceptonly model, based on evidence ratios (Table 4). To put this in terms of remigration interval, as nester abundance increases, the remigration interval (the number of years between nesting events) decreases, which is counter to our original hypothesis regarding density dependence.

\section{DISCUSSION}

\section{Temporal variability of demographic indicators}

The estimates of temporal variability for our demographic indicators give insight into how this population may have changed over $38 \mathrm{yr}$. Although the data did not support a linear trend in the time series, shortterm (3-4 yr) and decadal cycling were evident in both mean nester body length and breeding probability. The amount of variability estimated for these DIs of sea turtles is not unprecedented (Limpus et al. 2003, Troëng \& Chaloupka 2007, Limpus 2008, Phillips et al. 2014). Probably, several drivers exist for observed short-term trends and the degree of temporal variability. Possibly, new cohorts of neophyte nesters that recruit into the adult reproductive population contribute variation to the DIs. However, environmental or climate fluctuations could also be driving the temporal patterns (Carr \& Carr 1970, Broderick et al. 2001, Solow et al. 2002, Chaloupka \& Limpus 2005). Patterns in the DIs could be related to population density, because this population is increasing, based on multiple lines of evidence of trends in both adults and juveniles (Balazs \& Chaloupka 2004a, Chaloupka \& Balazs 2007, Chaloupka et al. 2008). However, our data suggest environmental stochasticity may be the dominant driver of annual variation in that the DI estimates vary annually and are not negatively correlated with nester abundance. 
We found decreasing turtle carapace lengths and breeding probability fairly early in the time series. Strong year classes recruiting into the adult reproductive population following harvest protection may be driving down the average carapace length in years with high recruitment. Size-selective harvest of sub-adults and smaller adults prior to ESA protection may have driven this population's response to conservation measures (Van Houtan \& Kittinger 2014). Egg harvest was extremely limited in the nesting beaches in the uninhabited NWHI, unlike many other sea turtle rookeries globally (Mast et al. 2011). In addition, fishermen selectively harvested smaller individuals (Balazs 1980, Witzell 1994, Kittinger et al. 2013, Van Houtan \& Kittinger 2014). In a historical analysis, Van Houtan \& Kittinger (2014) found that from 1948 to 1974, fishermen preferentially selected juvenile turtles (mean size $=30.5 \mathrm{~kg}$, $\sim 63.8 \mathrm{~cm} \mathrm{SCL}$ ), but towards the end of the fishery, average sizes of landed turtles increased dramatically. According to skeletochronology (skeletal growth increment analysis to estimate age), the mean size of turtles harvested corresponds to an estimated age of roughly $20 \mathrm{yr}$ (Zug et al. 2002). If age at maturity is 20 to $40 \mathrm{yr}$ (Balazs 1980, Zug et al. 2002, Hargrove \& Balazs 2012, Van Houtan et al. 2014), then we would expect to see sizeable changes in the adult population and in the age structure within the first $20 \mathrm{yr}$ after harvest was prohibited, as younger age classes experienced improved survivorship to maturity (Crowder et al. 1994). If eggs had also been harvested, recovery would likely have taken much longer, as has been observed in the Florida green turtle population (Chaloupka et al. 2008, NOAA \& USFWS 2015). Ultimately, examining changes in juvenile size distributions over time may be a better indicator of population-level changes than sizes of adults, as juvenile size distributions could give an early indication of changes in age structure as cohorts 'fill in' the gaps caused by exploitation (White et al. 2013).

Long-term datasets are necessary to capture the full range of variability for breeding probability and its inverse, remigration interval. Our estimates of breeding probability and body length suggest significant variability, but are in line with some recent estimates. Balazs et al. (2015) estimated remigration interval of Hawaiian green turtles, summing data from 1973 to 2013, to be 4 yr (breeding probability = 0.25), in contrast to an earlier estimate of $2.47 \mathrm{yr}$ (breeding probability $=0.404$; Table 2; Balazs 1980). Balazs et al. (2015) also found the mean body length for adult females in Hawaii to be $90.7 \mathrm{~cm}$ SCL, reduced from the original 1980 estimate of $92.2 \mathrm{~cm}$
SCL (Table 2; Balazs 1980, Van Buskirk \& Crowder 1994, Balazs et al. 2015). We also found smaller mean carapace lengths of nesters than those reported for green sea turtle populations elsewhere. For example, the mean SCL of nesters in Tortuguero, Costa Rica, was estimated to be $100.2 \mathrm{~cm}$, and in Heron Island, Australia, mean SCL was estimated at $102.4 \mathrm{~cm}$ compared to 89.2 to $91.7 \mathrm{~cm}$ in our study (Table 2; Van Buskirk \& Crowder 1994). The smaller average size of nesters may be due to the influx of younger animals into the Hawaiian population during the recovery period. Overall, our model selection procedures suggest that annual estimates of both breeding probability and body length are more accurate than constant estimates and that significant interannual variability exists.

Given that the top-ranked model for mean nester carapace length estimated a large range of mean sizes annually, suggesting potential cohort effects, it is surprising to see so little difference in the estimated sizes of newly tagged turtles, i.e. nominal neophytes, and veteran nesters $\left(\sim 0.5 \mathrm{~cm}\right.$ difference $\left.\mathrm{yr}^{-1}\right)$. In contrast, in the southern Great Barrier Reef, veteran turtles are on average $3 \mathrm{~cm}$ larger than neophyte nesters (Limpus 2008). There are at least 2 possible explanations for our result. First, newly mature green turtles may not all be tagged upon their first reproductive year, leading to inflated length estimates of nominal neophytes. Given the amount of effort on the nesting beach, it is unlikely that neophyte nesters are consistently missed by nest surveyors if those turtles are coming to East Island exclusively. But detectability could be lower for neophytes if those females have low nest site fidelity as they recruit into the adult population, i.e. some neophytes nest at other rookeries in the Hawaiian Islands, and then nest at East Island subsequently (Limpus et al. 2003, Tucker 2010). At least 95 individuals are recorded as nesting at East Island and other outlying islands in the NWHI at some time, corresponding to a $3 \%$ rate of 'infidelity' (Pacific Islands Fisheries Science Center unpublished reports). However, surveys at the other nesting rookeries in the NWHI are infrequent and opportunistic, so it is hard to quantify survey effort outside of East Island. A second explanation for the size distribution overlap between newly tagged and veteran nesters is variable growth and size at maturity. Growth rates vary widely among individual turtles, with little or no growth following maturation (Balazs \& Chaloupka 2004a, Goshe et al. 2010, Avens et al. 2012, 2013). In captive-reared green sea turtles that were monitored from birth to past sexual maturity, wide variations in both age and 
size at maturity were observed (Bjorndal et al. 2013). This variability is likely to obscure distinctions between sizes of neophytes and veteran nesters. Further investigations of site fidelity and size at maturity, as well as development of physiological methods to identify newly mature turtles are needed to fully understand the implications of shifts in nester size during population recovery.

We did not find evidence that survival rates varied over time from 1980 to 2009 ( $S=0.929,95 \%$ CI: 0.924-0.933). Following ESA protection, survival rates were expected to increase, especially as adults were targeted for harvest towards the end of the fishery. However, survival rates had likely already increased by 1980 (the first year included in the MSORD model), as there had been a campaign to protect green sea turtles in Hawaii in the 1970s; the state of Hawaii passed regulations restricting harvest starting in 1974 (Balazs 1980), and ESA protection formally occurred in 1978. Our results are comparable to the findings of Van Houtan et al. (2014), who used matrix models to deterministically estimate survival rates in Hawaiian green sea turtles (Table 2). To put this into context, adult female survival rates in Hawaii are relatively high compared to other populations. For example, in Costa Rica, where nesting turtles are impacted by fisheries in Nicaraguan waters, adult female survival is estimated to be 0.85 (95\% CI: 0.83-0.87) and in Venezuela, where anthropogenic impacts are high, adult female survival is estimated to be 0.79 (95\% CI: 0.73-0.84), but in Australia, where anthropogenic impacts are minimal, adult female survival is estimated to be 0.9485 (95\% CI: 0.92-0.98; Chaloupka \& Limpus 2005, Troëng \& Chaloupka 2007, Garcia-Cruz et al. 2015). Our study is apparently the first to test whether the survival rate for Hawaiian adult females has changed since harvest was prohibited; however, a constant estimate was supported by model selection. In population models, it may be simplest to use a time-invariant constant estimate of survival, albeit with consideration of uncertainty, unless there is strong evidence for a change in adult survival over time. Mark-recapture analysis is a valuable tool for detecting such changes, which could have profound effects on population productivity (Bjorndal et al. 2010).

\section{Demographic indicators as a function of nester abundance}

We did not see a decrease in breeding probability as the Hawaiian green turtle population recovered, as might be predicted by density-dependence. This result suggests that either density-independent factors (e.g. climate) are driving remigration, or that the population is still below carrying capacity and not yet regulated by population density. In that case, the result also suggests that the Hawaiian population is still in the process of recovery and has not yet reached equilibrium. This result is in contrast to previous research on a discrete foraging aggregation off the Big Island of Hawaii that suggested the aggregation is at carrying capacity, and green sea turtles there experience intra- and inter-specific competition for macroalgal food sources (Wabnitz et al. 2010). Previous research on the carrying capacity of East Island for green sea turtle nesting suggests that the island could support many more nesters than presently observed (Tiwari et al. 2010). Our current findings and previous research suggest that while some turtles that frequent certain foraging areas may be resource limited and experience low growth rates (Balazs \& Chaloupka 2004a), this limitation is not borne out in the primary nesting area and does not appear to influence breeding probability, at least not at the population level.

Because of the observed positive relationship of breeding probability, or its inverse remigration interval, with nester abundance, breeding probability shows promise as an indicator of nester abundance during periods of population recovery. Hays (2000) found in his theoretical models that when variability in forage quality was included, remigration interval was variable and drove interannual variation in nesting numbers, and interannual variation remained constant regardless of population size. Understanding the relationship between demographic indicators and population size is valuable for sea turtle populations that can only be monitored over a small proportion of their geographic range. Our results also highlight the importance of carefully interpreting raw counts of increased nester abundance, as a positive trend could be attributable to increased nesting frequency - a greater breeding probability-and not necessarily a true increase in population abundance (Bjorndal et al. 2010). If breeding probability increases with nester abundance, as we have reported, estimated recovery rates may be inflated if only raw counts of nests or nesters (rather than the identities of nesters, as we performed in this study) are monitored across seasons (Pfaller et al. 2013). In the future, our results could be compared to other recovering populations of green sea turtles to determine if these are general trends. 
Acknowledgements. We sincerely thank the efforts of the Pacific Islands Fisheries Science Center staff and volunteers who conducted the nesting surveys at East Island, French Frigate Shoals, over the course of 4 decades. We thank K. Dugger, B. Kendall, and A. Sterner for assistance with Program Mark and the MSORD models. The manuscript was greatly improved by comments from N. S. Arbuckle, S. Jennings, M. Ramirez, and 2 anonymous reviewers. S.E.P. was supported by a National Oceanic and Atmospheric Administration / Sea Grant Population Dynamics Graduate Fellowship, a Great Lakes National Graduate Scholarship, an Oregon Lottery Scholarship, and a Thomas G. Scott Scholarship. Publication of this paper was supported, in part, by the Thomas G. Scott Publication Fund.

\section{LITERATURE CITED}

Anderson DR, Burnham KP, Thompson WL (2000) Null hypothesis testing: problems, prevalence, and an alternative. J Wildl Manag 64:912-923

> Avens L, Goshe LR, Harms CA, Anderson ET and others (2012) Population characteristics, age structure, and growth dynamics of neritic juvenile green turtles in the northeastern Gulf of Mexico. Mar Ecol Prog Ser 458: 213-229

> Avens L, Goshe LR, Pajuelo M, Bjorndal KA and others (2013) Complementary skeletochronology and stable isotope analyses offer new insight into juvenile loggerhead sea turtle oceanic stage duration and growth dynamics. Mar Ecol Prog Ser 491:235-251

Balazs GH (1980) Synopsis of biological data on the green turtle in the Hawaiian islands. NOAA National Marine Fisheries Service, Honolulu, HI

Balazs G, Chaloupka M (2004a) Spatial and temporal variability in somatic growth of green sea turtles (Chelonia mydas) resident in the Hawaiian Archipelago. Mar Biol 145:1043-1059

Balazs G, Chaloupka M (2004b) Thirty-year recovery trend in the once depleted Hawaiian green sea turtle stock. Biol Conserv 117:491-498

Balazs GH, Van Houtan KS, Hargrove SA, Brunson SM, Murakawa SKK (2015) A review of the demographic features of Hawaiian green turtles (Chelonia mydas). Chelonian Conserv Biol 14:119-129

Bjørkvoll E, Grøtan V, Aanes S, Sæther BE, Engen S, Aanes R (2012) Stochastic population dynamics and life-history variation in marine fish species. Am Nat 180:372-387

Bjorndal KA, Bolten AB, Chaloupka MY (2000) Green turtle somatic growth model: evidence for density dependence. Ecol Appl 10:269-282

Bjorndal KA, Bowen BW, Chaloupka M, Crowder LB and others (2010) Assessment of sea-turtle status and trends: integrating demography and abundance, $1^{\text {st }}$ edn. The National Academies Press, Washington, DC

> Bjorndal KA, Parsons J, Mustin W, Bolten AB (2013) Threshold to maturity in a long-lived reptile: interactions of age, size, and growth. Mar Biol 160:607-616

Bolker BM, Brooks ME, Clark CJ, Geange SW, Poulsen JR, Stevens MHH, White JSS (2009) Generalized linear mixed models: a practical guide for ecology and evolution. Trends Ecol Evol 24:127-135

Bowen BW, Meylan AB, Ross JP, Limpus CJ, Balazs GH, Avise JC (1992) Global population structure and natural history of the green turtle (Chelonia mydas) in terms of matriarchal phylogeny. Evolution 46:865-881

Broderick AC, Godley BJ, Hays GC (2001) Trophic status drives interannual variability in nesting numbers of marine turtles. Proc R Soc Lond B Biol Sci 268:1481-1487

Burnham K, Anderson D (2002) Model selection and multimodel inference: a practical information-theoretic approach. Springer, New York, NY

Cam E, Link WA, Cooch EG, Monnat JY, Danchin E (2002) Individual covariation in life history traits: seeing the trees despite the forest. Am Nat 159:96-105

Campbell CL, Lagueux CJ (2005) Survival probability estimates for large juvenile and adult green turtles (Chelonia mydas) exposed to an artisanal marine turtle fishery in the western Caribbean. Herpetologica 61:91-103

> Carr A, Carr MH (1970) Modulated reproductive periodicity in Chelonia. Ecology 51:335-337

> Caut S, Hulin V, Girondot M (2006) Impact of densitydependent nest destruction on emergence success of Guianan leatherback turtles (Dermochelys coriacea). Anim Conserv 9:189-197

Chaloupka M, Balazs G (2007) Using Bayesian state-space modelling to assess the recovery and harvest potential of the Hawaiian green sea turtle stock. Ecol Model 205: 93-109

Chaloupka M, Limpus C (1996) Heuristic modeling of Chelonia mydas population dynamics - southern Great Barrier Reef. In: Keinath JA, Barnard DE, Musick JA, Bell BA (compilers) Proc 15th Annual Symposium on Sea Turtle Biology and Conservation. SEFSC, p 66-69. www. internationalseaturtlesociety.org/\#/Proceedings

Chaloupka M, Limpus C (2005) Estimates of sex- and ageclass-specific survival probabilities for a southern Great Barrier Reef green sea turtle population. Mar Biol 146: 1251-1261

Chaloupka M, Bjorndal KA, Balazs GH, Bolten AB and others (2008) Encouraging outlook for recovery of a once severely exploited marine megaherbivore. Glob Ecol Biogeogr 17:297-304

Conover DO, Munch SB, Arnott SA (2009) Reversal of evolutionary downsizing caused by selective harvest of large fish. Proc R Soc Lond B Biol Sci 276:2015-2020

Cooch EG, White GC (eds) (2013) Program Mark: a gentle introduction, $13^{\text {th }}$ edn. Fort Collins, CO. www.phidot.org/ software/mark/docs/book/

> Crowder LB, Crouse DT, Heppell SS, Martin TH (1994) Predicting the impact of turtle excluder devices on loggerhead sea turtle populations. Ecol Appl 4:437-445

Dizon AE, Balazs GH (1982) Radio telemetry of Hawaiian green turtles at their breeding colony. Mar Fish Rev 44: $13-20$

> Dutton PH, Balazs GH, LeRoux RA, Murakawa SKK, Zarate P, Martínez LS (2008) Composition of Hawaiian green turtle foraging aggregations: mtDNA evidence for a distinct regional population. Endang Species Res 5:37-44

> Garcia-Cruz MA, Lampo M, Peñaloza CL, Kendall WL, Solé G, Rodriguez-Clark KM (2015) Population trends and survival of nesting green sea turtles Chelonia mydas on Aves Island, Venezuela. Endang Species Res 29:103-116

Gerber LR, Heppell SS (2004) The use of demographic sensitivity analysis in marine species conservation planning. Biol Conserv 120:121-128

Goshe L, Avens L, Scharf F, Southwood A (2010) Estimation of age at maturation and growth of Atlantic green turtles (Chelonia mydas) using skeletochronology. Mar Biol 157: 1725-1740 
Gotthard K, Nylin S (1995) Adaptive plasticity and plasticity as an adaptation: a selective review of plasticity in animal morphology and life history. Oikos 74:3-17

Hargrove SK, Balazs GH (2012) Coming of age: four decades of tagging sheds light on time to maturity for Hawaiian green turtles. In: Jones TT, Wallace BP (compilers) Proc 31st Annual Symposium on Sea Turtle Biology and Conservation. National Oceanic and Atmospheric Administration, San Diego, CA, p 42. www.internationalseaturtle society.org/\#/Proceedings

Hays GC (2000) The implications of variable remigration intervals for the assessment of population size in marine turtles. J Theor Biol 206:221-227

Heppell SS, Crowder LB, Crouse DT (1996) Models to evaluate headstarting as a management tool for long-lived turtles. Ecol Appl 6:556-565

Holling CS (1973) Resilience and stability of ecological systems. Annu Rev Ecol Syst 4:1-23

Hutchings JA (1996) Spatial and temporal variation in the density of northern cod and a review of hypotheses for the stock's collapse. Can J Fish Aquat Sci 53:943-962

> Hutchings JA (2000) Collapse and recovery of marine fishes. Nature 406:882-885

Hutchings JA, Reynolds J (2004) Marine fish population collapses: consequences for recovery and extinction risk. Bioscience 54:297-309

> Hutchings JA, Myers RA, Garcia VB, Lucifora LO, Kuparinen A (2012) Life-history correlates of extinction risk and recovery potential. Ecol Appl 22:1061-1067

Johnson JB, Omland KS (2004) Model selection in ecology and evolution. Trends Ecol Evol 19:101-108

Kendall W (2013) The 'robust design.' In: Cooch EG, White GC (eds) Program Mark: a gentle introduction, $13^{\text {th }}$ edn. Fort Collins, CO, p 15-1-15-51. www.phidot.org/software/ mark/docs/book/

Kendall WL, Bjorkland R (2001) Using open robust design models to estimate temporary emigration from capturerecapture data. Biometrics 57:1113-1122

Kendall WL, Nichols JD (2002) Estimating state-transition probabilities for unobservable states using capturerecapture/resighting data. Ecology 83:3276-3284

Kittinger JN, Van Houtan KS, McClenachan LE, Lawrence AL (2013) Using historical data to assess the biogeography of population recovery. Ecography 36:868-872

Kuparinen A, Merila J (2007) Detecting and managing fisheries-induced evolution. Trends Ecol Evol 22:652-659

Lebreton J, Burnham K, Clobert J, Anderson D (1992) Modeling survival and testing biological hypotheses using marked animals: a unified approach with case-studies. Ecol Monogr 62:67-118

Limpus C (2008) A biological review of Australian marine turtle species. 2. Green turtle, Chelonia mydas (Linnaeus). Queensland Environmental Protection Agency, Brisbane

Limpus C, Chaloupka M (1997) Nonparametric regression modelling of green sea turtle growth rates (southern Great Barrier Reef). Mar Ecol Prog Ser 149:23-34

Limpus CJ, Miller JD, Parmenter CJ, Limpus DJ (2003) The green turtle, Chelonia mydas, population of Raine Island and the northern Great Barrier Reef: 1843-2001. Mem Queensl Mus 49:349-440

> Littell RC, Henry PR, Ammerman CB (1998) Statistical analysis of repeated measures data using SAS procedures. J Anim Sci 76:1216-1231

Mast RB, Hutchinson BJ, Wallace BP, Yarnell L, Hoyt S (2011) The most valuable reptile in the world: the green turtle. Sea Turtle Status, Arlington, VA

- Mazaris A, Matsinos Y (2006) An individual based model of sea turtles: investigating the effect of temporal variability on population dynamics. Ecol Model 194:114-124

Miller JD (1997) Reproduction in sea turtles. In: Lutz PL, Musick JA (eds) The biology of sea turtles. CRC Press, Boca Raton, FL, p 51-82

NOAA (National Oceanic and Atmospheric Administration), USFWS (United States Fish and Wildlife Service) (2015) Endangered and threatened species; identification and proposed listing of eleven distinct population segments of green sea turtles (Chelonia mydas) as endangered or threatened and revision of current listings. Fed Regist 80: 15272-15337

NOAA Office of Protected Resources (2014) Green sea turtle. Office of Protected Resources - NOAA Fisheries, Washington, DC. www.nmfs.noaa.gov/pr/species/turtles/ green.html

Nurzia Humburg I, Balazs GH (2014) Forty years of research: recovery records of green turtles observed or originally tagged at French Frigate Shoals in the Northwestern Hawaiian Islands, 1973-2013. NOAA, Fisheries, Honolulu, HI

Pfaller JB, Bjorndal KA, Chaloupka M, Williams KL, Frick MG, Bolten AB (2013) Accounting for imperfect detection is critical for inferring marine turtle nesting population trends. PLOS ONE 8:e62326

> Phillips KF, Mansfield KL, Die DJ, Addison DS (2014) Survival and remigration probabilities for loggerhead turtles (Caretta caretta) nesting in the eastern Gulf of Mexico. Mar Biol 161:863-870

Pollock KH (1982) A capture-recapture design robust to unequal probability of capture. J Wildl Manag 46:752-757

Richards PM, Epperly SP, Heppell SS, King RT and others (2011) Sea turtle population estimates incorporating uncertainty: a new approach applied to western North Atlantic loggerheads Caretta caretta. Endang Species Res 15:151-158

Richardson JI, Hall DB, Mason PA, Andrews KM, Bjorkland R, Cai Y, Bell R (2006) Eighteen years of saturation tagging data reveal a significant increase in nesting hawksbill sea turtles (Eretmochelys imbricata) on Long Island, Antigua. Anim Conserv 9:302-307

Rochet MJ (2000a) A comparative approach to life-history strategies and tactics among four orders of teleost fish. ICES J Mar Sci 57:228-239

Rochet MJ (2000b) May life history traits be used as indices of population viability? J Sea Res 44:145-157

Sæther BE, Bakke Ø (2000) Avian life history variation and contribution of demographic traits to the population growth rate. Ecology 81:642-653

Sæther BE, Engen S, Moller AP, Weimerskirch H and others (2004) Life-history variation predicts the effects of demographic stochasticity on avian population dynamics. Am Nat 164:793-802

> Shelton AO, Mangel M (2011) Fluctuations of fish populations and the magnifying effects of fishing. Proc Natl Acad Sci USA 108:7075-7080

Solow AR, Bjorndal KA, Bolten AB (2002) Annual variation in nesting numbers of marine turtles: the effect of sea surface temperature on re-migration intervals. Ecol Lett 5:742-746

> Thorson JT, Monnahan CC, Cope JM (2015) The potential impact of time-variation in vital rates on fisheries management targets for marine fishes. Fish Res 169:8-17 
Tiwari M, Balazs GH, Hargrove S (2010) Estimating carrying capacity at the green turtle nesting beach of East Island, French Frigate Shoals. Mar Ecol Prog Ser 419: 289-294

Troëng S, Chaloupka M (2007) Variation in adult annual survival probability and remigration intervals of sea turtles. Mar Biol 151:1721-1730

Tucker AD (2010) Nest site fidelity and clutch frequency of loggerhead turtles are better elucidated by satellite telemetry than by nocturnal tagging efforts: implications for stock estimation. J Exp Mar Biol Ecol 383:48-55

Van Buskirk J, Crowder L (1994) Life-history variation in marine turtles. Copeia 1994:66-81

Van Houtan KS, Kittinger JN (2014) Historical commercial exploitation and the current status of Hawaiian green turtles. Biol Conserv 170:20-27

Van Houtan KS, Hargrove SK, Balazs GH (2014) Modeling sea turtle maturity age from partial life history records. Pac Sci 68:465-477

Editorial responsibility: Paolo Casale, Rome, Italy
Wabnitz CCC, Balazs G, Beavers S, Bjorndal KA and others (2010) Ecosystem structure and processes at Kaloko Honokohau, focusing on the role of herbivores, including the green sea turtle Chelonia mydas, in reef resilience. Mar Ecol Prog Ser 420:27-44

Wetherall JA, Balazs GH, Yong YY (1998) Statistical methods for green turtle nesting surveys in the Hawaiian Islands. In: Epperly SP, Braun J (compilers) Proc 17th Annual Sea Turtle Symposium, p 295-297. www.inter nationalseaturtlesociety.org/\#/Proceedings

White JW, Botsford LW, Hastings A, Baskett ML, Kaplan DM, Barnett LAK (2013) Transient responses of fished populations to marine reserve establishment. Conserv Lett 6:180-191

Witzell WN (1994) The origin, evolution and demise of the U.S. sea turtle fisheries. Mar Fish Rev 56:8-23

Zug G, Balazs G, Wetherall J (2002) Age and growth of Hawaiian green sea turtle (Chelonia mydas): an analysis based on skeletochronology. Fish Bull 100:117-127

Submitted: August 31, 2015; Accepted: July 24, 2016

Proofs received from author(s): September 14, 2016 